\title{
Eating Patterns of Pacific Children at Age 14 Years; Pacific Islands Families Study ${ }^{\dagger}$
}

\author{
Shabnam Jalili Moghaddam 1,*, Elaine Rush ${ }^{2}$ and Gael Janine Mearns ${ }^{3}$ \\ 1 Centre for Pacific Health and Development Research, School of Public Health and Psychosocial Studies, \\ Auckland University of Technology, Auckland 1142, New Zealand \\ 2 AUT Food Network, Auckland University of Technology, Auckland 1142, New Zealand; \\ elaine.rush@aut.ac.nz \\ 3 School of Clinical Sciences, Auckland University of Technology 1142, Auckland, New Zealand; \\ gael.mearns@aut.ac.nz \\ * Correspondence: shabnam.jalili@aut.ac.nz \\ † Presented at the 2018 Nutrition Society of New Zealand Annual Conference, Auckland, New Zealand, \\ 28-30 November 2018.
}

Published: 3 April 2019

Background: The variety, quality and quantity of foods consumed and eating patterns influence the development of non-communicable diseases. The eating patterns of New Zealand Pacific children are important to study because the number of Pacific children in New Zealand is increasing and this population has a high risk for excessive weight gain, and increased risk for developing type 2 diabetes mellitus. The aim of this investigation was to identify eating patterns of foods habitually consumed by 14-year-old Pacific children in the Pacific Islands Families study.

Methods: Dietary habit questionnaires were completed by 931 children; (463 girls, 468 boys). Height and weight were also measured. Cluster analysis was applied to derive the eating patterns.

Results: Boys weighed more $(p=0.039)$ and were taller than girls $(p=0.001)$. Almost two thirds of the children were overweight or obese. Boys were more likely than girls to not be overweight or obese $\left(\chi^{2} 12.70, p=0.005\right)$. Four eating patterns were identified: 'occasional' (prioritises takeaways and high fat and sugar foods), 'seafood'; 'basic and staples' (prioritises milk, fruit and vegetables); and 'meat and bread'. The 'occasional' eating pattern dominated by relatively poor nutrient and highenergy food was the strongest identified eating pattern. Proportionally there were more girls than boys within the 'seafood' and 'basic and staples' patterns and less girls than boys in the 'occasional' and 'meat and bread' patterns $\left(\chi^{2} 8.9, p=0.03\right)$. Boys $(57 \%)$ were more likely to be present in the 'meat and bread' pattern than girls $(43 \%)\left(\chi^{2} 4.3, p=0.04\right)$.

Conclusions: The gender differences should be explored further. The strongest identified eating pattern was nutrient poor and energy dense, highlighting the need for multi-sectorial action involving the food industry and commercial outlets so that healthier food environments and affordable food choices are available for Pacific children.

(C) 2019 by the authors. Licensee MDPI, Basel, Switzerland. This article is an open access article distributed under the terms and conditions of the Creative Commons Attribution (CC BY) license (http://creativecommons.org/licenses/by/4.0/). 